\title{
Cranioplasty Using Autologous Fasciae Latae Graft for Nasal Bone Fracture Repair in a Dog
}

\author{
Annalú Pinton Ferreira', Alana Lucena Oliveira², Giuliano Queiroz Mostachio', Joana Zafalon Ferreira', \\ Stephanie Fernandez ${ }^{3}$, Talita Floering Brêda Souza', Andrigo Barboza de Nardi \& Victor José Vieira Rossetto'
}

\begin{abstract}
Background: In facial reconstruction, several kinds of grafts can be used, like bone grafting, cutaneous grafting, biological membranes, fasciae latae, biomaterials, and others. The advantage of using fasciae latae in the tissue reparation is the need of little blood supply, making it a viable option in the restoration of biological functions. The objective of this study was to describe the case of a female poodle, 12-year-old, and with subcutaneous emphysema due to fracture of the nasal bone, submitted to cranioplasty using fasciae latae.

Case: It was attended a 12-year-old female poodle due to a traumatic brain injury. At physical examination, the animal had presented facial swelling and respiratory distress with inspiratory effort. Additionally, were verified subcutaneous emphysema and a depression in the nasal plane region with crepitus on palpation. Radiographic examinations revealed nasal bone and maxilla fractures. The animal was submitted to cranioplasty for nasal bone fracture repair. To access the nasal bone and frontal sinus was performed an incision in the dorsal midline from the level of medial orbital rim to the nasal plane. The subcutaneous tissue was divulsioned to allow the exposure of the nasal bone fracture, whose small fragments prevented the internal fixation. The bone defect was then repaired using free autologous fasciae latae of $2 \mathrm{~cm}$ wide x $3 \mathrm{~cm}$ long, sutured to the periosteum. Subcutaneous emphysema gradually decreased until its resolution at three days postoperatively. The surgical wound had complete healing at 10 days after surgery without concomitant complications.

Discussion: The choice of the reconstructive technique is based on the operative planning and the surgeon's experience. In the present case we opted for the autologous fasciae latae graft since its ready availability and lesser predisposition to immunogenic sensibilization and rejection. In addition, we opted for the autologous fasciae latae graft because it is an occlusive material that would prevent the air flow through it during the inspiration and expiration, and consequently the aggravation of the subcutaneous emphysema. In fact, the resolution of the subcutaneous emphysema occurred three days after grafting. Furthermore, the resolution of the subcutaneous emphysema was determined by the lower retraction of the autologous fasciae latae graft due to the scar fibrous tissue deposition. The choice of the reconstructive technique is also based on the viability of the recipient bed, which should provide adequate blood supply for the reception of the free graft. In the present case, however, the bone defect did not provide adequate blood supply and structural support. Due to this, the autologous fasciae latae graft was crucial to the verified results, since it requires less blood supply and structural support to remain the graft viable. We concluded that the autologous fasciae latae graft may be a viable option for the anatomical and functional reconstruction of traumatic lesions localized in the skull, particularly the nasal bone, due to the satisfactory follow-up in the present case without the occurrence of complications. A larger sample size, however, it is necessary to evaluate the real effectiveness of the autologous fasciae latae graft in reconstructive skull surgery on small animals.
\end{abstract}

Keywords: graft, autograft, reconstruction, skull. 


\section{INTRODUCTION}

In facial reconstruction may be used various types of grafts, such as skin or bone grafts, biological membranes, fasciae latae, and others biomaterials [9].

The fasciae latae is composed of fibrous tissue that externally covers the thigh muscles [4]. It highlights in the reconstruction of a several damaged tissues due to its resistance, little possibility of retraction, ready availability and need of little blood supply $[1,6,8]$.

The aim of the present report is to describe the case of a 12-year-old female poodle with nasal bone fracture, submitted to cranioplasty using autologous fasciae latae graft.

\section{CASE}

It was attempted a 12-year-old female poodle with traumatic brain injury after a car accident. At physical examination, the animal had presented facial swelling and respiratory distress with inspiratory effort. Additionally, were verified subcutaneous emphysema and a depression in the nasal plane region with crepitus on palpation.

Laterolateral and dorsoventral radiographic views revealed nasal bone and maxilla fractures (Figure 1).

The animal was submitted to cranioplasty for nasal bone fracture repair. For this, anesthetic induction was performed with propofol dose effect $\left(\operatorname{Propovan}^{\circledR}\right)^{1}$, administered intravenously. The anesthetic maintenance was performed with isoflurane (Isoforine $\left.{ }^{\circledR}\right)^{1}$ diluted in oxygen.

To access the nasal bone and frontal sinus was performed an incision in the dorsal midline from the level of medial orbital rim to the nasal plane [8]. The subcutaneous tissue was divulsioned to allow the exposure of the nasal bone fracture and bone fragments into the frontal sinus. Due to the small size of bone fragments, they were discarded and the internal fixation was not performed.

The bone defect was repaired using free autologous fasciae latae of $2 \mathrm{~cm}$ wide $\times 3 \mathrm{~cm}$ long. The graft was sutured to the adjacent periosteum in a simple interrupted pattern using 3-0 monofilament polyamide (Figure 2). The subcutaneous was closed in a cushing pattern using 3-0 polyglactin 910 . The skin was closed in a simple interrupted pattern using 2-0 monofilament polyamide.

Postoperative management consisted of $5 \mathrm{mg}$ $\mathrm{kg}^{-1}$ of enrofloxacin $\left(\text { Baytril }^{\circledR}\right)^{2}$, orally, BID, for 10 days; $4 \mathrm{mg} \mathrm{kg}^{-1}$ of tramadol hydrochloride (Trama-
$\left.\operatorname{don}^{\circledR}\right)^{1}$, subcutaneously, BID, for seven days; and $2 \mathrm{mg}$ $\mathrm{kg}^{-1}$ of ranitidine hydrochloride (Cloridrato de ranitidinainjetável $)^{3}$, subcutaneously, BID, for 10 days. The cleaning of the surgical wound was carried out daily using $0.5 \%$ clorexidine aqueous solution.

The subcutaneous emphysema gradually decreased until its resolution at three days postoperatively. The surgical wound had complete healing at 10 days postoperatively without complications. The animal was revaluated at 30 days postoperatively and do not showed any respiratory abnormalities or at the surgical site.

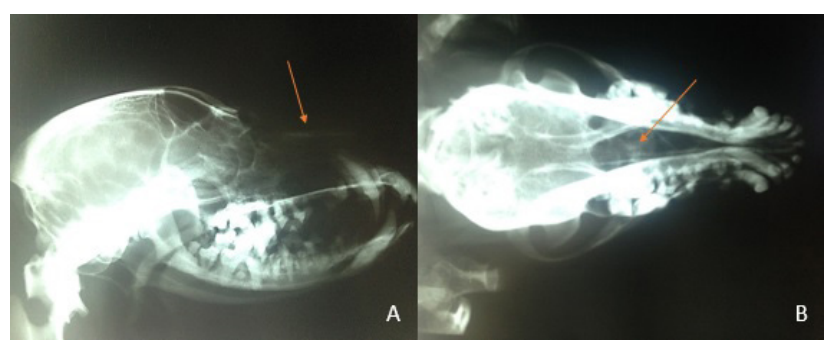

Figure 1. Laterolateral radiographic view of the skull of the reported dog with traumatic brain injury. Note the nasal bone and maxilla fractures (arrow) with small bone fragments into the nasal cavity.

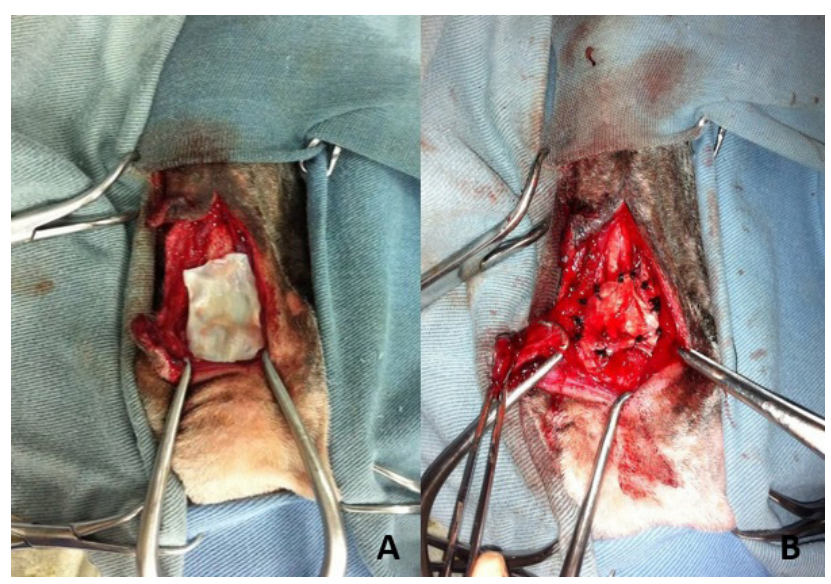

Figure 2. Transoperatory of the dog submitted to cranioplasty using autologous fasciae latae graft for nasal bone fracture repair. Note the rectangular free graft sutured to the periosteum in a simple interrupted pattern.

\section{DISCUSSION}

The choice of the reconstructive technique is based on the operative planning and the surgeon's experience [3,7]. In the present case we opted for the autologous fasciae latae graft, since its ready availability and lesser predisposition to immunogenic sensibilization and rejection than xenogenous or allogenous grafts $[2,7,8,10]$.

Another alternative is the use of non-absorbable materials as metal meshes and polypropylene meshes, 
or biological membranes [10]. Some of these materials, however, would enable the air flow through the graft during the inspiration and expiration. Therefore, we opted for the autologous fasciae latae graft because it is an occlusive material that would prevent the worsening of the subcutaneous emphysema. The resolution of the subcutaneous emphysema was also determined by the lower retraction of the autologous fasciae latae graft due to the scar fibrous tissue deposition [1,8]. In fact, the resolution of subcutaneous emphysema occurred three days postoperatively.

Additionally, the choice of the reconstructive technique is based on the viability of the recipient bed, which should provide adequate blood supply for the nutrition of the free graft in the earlier stages after surgery [7]. In the present case, however, the bone defect did not provide adequate blood supply and structural support. Due to this, the autologous fasciae latae graft was essential for the verified results, since it requires less blood supply and structural support to remain the graft viable [8].

It was concluded that the autologous fasciae latae graft may be a viable option for the anatomical and functional reconstruction of traumatic lesions localized in the skull, particularly the nasal bone, due to the satisfactory follow-up in the present case without the occurrence of complications. A larger sample size, however, it is necessary to evaluate the real effectiveness of the autologous fasciae latae graft in reconstructive skull surgery on small animals.

\section{MANUFACTURERS}

${ }^{1}$ Laboratório Cristália. São Paulo, SP, Brazil.

${ }^{2}$ Bayer Saúde Animal. São Paulo, SP, Brazil.

${ }^{3}$ Medley Farmacêutica Ltda. Campinas, SP, Brazil.

Declaration of interest. The authors report no conflicts of interest. The authors alone are responsible for the content and writing of the paper.

\section{REFERENCES}

1 Carneiro C.G \& Sennes L.U. 2005. Avaliação da deposição de colágeno após implante de fáscia lata e de gordura na prega vocal de coelho: estudo histomorfométrico. Brazilian Journal Of Otorhinolaryngology. 71(6): 798-802.

2 Chiu T. \& Burd A. 2005. "Xenograft" dressing in the treatment of burns. Clinics in Dermatology. 23(4): 419-423.

3 Chung K.C., Swanson J.A \& Schmitz D. 2009. Introducing evidence based medicine to plastic and reconstructive surgery. Journal of Plastic and Reconstrutive Surgery. 123: 1385-1389.

4 Getty R., Sisson S. \& Grossman J.D. 1986. Anatomia dos Animais Domésticos. 5.ed. Rio de Janeiro: Guanabara Koogan, 2048p.

5 Johnson L.A. 2014. Management of specific fractures. In: Fossum T.W., Curtis W.D., Horn C.V., Johnson A.L., Macphail C.M., Macphail C.M., Radlinsky M.G., Schulz K.S. \& Willard M.D. (Eds). Small Animal Surgery Textbook. 4th edn. St. Louis: Elsevier, pp.1106-1215.

6 Kirschner D.A \& Pigossi N. 1982. Transplante de derme, gordura, fáscia, cartilagem e osso. In: Sucena R.C. (Ed). Cirurgia Plástica. São Paulo: Roca, pp.69-88.

7 Macphail C.M. 2014. Wound management. In: Fossum T.W., Curtis W.D., Horn C.V., Johnson A.L., Macphail C.M., Macphail C.M., Radlinsky M.G., Schulz K.S. \& Willard M.D. (Eds). Small Animal Surgery Textbook. 4th edn. St. Louis: Elsevier, pp.190-207.

8 Pavletic M.M. 2007. Tegumento. In: Slatter D. (Ed). Manual de Cirurgia de Pequenos Animais. 3.ed. Barueri: Manole, pp.250-258.

9 Potter J.K. \& Ellis I.E. 2004. Biomaterials for reconstruction of the internal orbit. Journal of Oral Maxillofacial Surgery. 62: 1280-1297.

10 Ober C., Muste A., Oana L., Mates N., Beteg F. \& Veres S. 2008. Using of prosthetic biomaterials in large animals: modern concepts about abdominal wall defects approach. Journal of Central European Agriculture. 9(3): 575-580. 